\title{
Assessment of Levels of Mercury in Human Breast Milk in Obuasi Municipality, Ghana
}

\author{
Dinah Asamoah-Antwi ${ }^{1 *}$, Sam Adu Kumi ${ }^{1,2}$, Joseph R. Fianko ${ }^{1}$ \\ ${ }^{1}$ Department of Nuclear Sciences and Applications, School of Nuclear and Allied Sciences, University of Ghana, P.O. Box LG \\ 80 Legon, Ghana \\ ${ }^{2}$ Chemicals Control and Management Centre, Environmental Protection Agency, P.O. Box M326 Accra, Ghana
}

Corresponding Author Email: dasamoah-antwi@st.ug.edu.gh

https://doi.org/10.18280/eesrj.070301

Received: 2 June 2020

Accepted: 10 August 2020

\section{Keywords:}

breastfeeding, total mercury, methylmercury, hazard quotient, infants

\begin{abstract}
This study was conducted to assess the levels of mercury in breast milk and estimated the health risk to breastfed infants in Obuasi Municipality. Most women living in mining communities within Ghana often depend on mining activities for their livelihood hence the study. Forty- eight (48) individual breast milk samples were collected from mothers in selected health facilities in Obuasi town and its environs. Total mercury concentrations were determined in the breast milk samples using advanced mercury analyser (AMA254 Altec s.r.o, Czech Republic). Methylmercury levels were determined using highperformance liquid chromatography linked to inductively coupled plasma mass spectrometry (HPLC-ICP-MS) with isotope dilution. The mean concentrations of Total mercury and Methylmercury in the breast milk were 0.4043 and $0.1829 \mu \mathrm{g} / \mathrm{L}$ respectively. Total mercury and methylmercury concentrations ranged from 0.080 to $2.320 \mu \mathrm{g} / \mathrm{L}$ and 0.008 to $0.734 \mu \mathrm{g} / \mathrm{L}$ respectively. The estimated intake obtained in this study was lower than the reference dose established by the US EPA $(0.3 \mu \mathrm{g} / \mathrm{kg} /$ day $)$. However, the hazard quotients evaluated showed that the one-month-old infants had hazard quotient above the 0.2 , therefore indicating that there is a health concern for such infants and need to be managed. The study information on the maternal toxic burden.
\end{abstract}

\section{INTRODUCTION}

Breast milk is the natural and superior food for infants, containing the optimal composition to meet their nutritional needs in early life. It has antibodies and enzymes that protect the child from diarrhoea and acute respiratory infections [1]. As a way to minimize infants' mortality, six months of exclusive breastfeeding is recommended by the World Health Organization (WHO) and the United Nations International Children's Emergency Fund (UNICEF) [2, 3].

Research has also shown that breast milk has become a habitat for some metals such as mercury from the environment across the world as well as some persistent organic pollutant $[4,5]$. Oskarsson et al. 1995 found in their research that exposure of Inorganic $\mathrm{Hg}$ from amalgam was linked to blood and milk mercury levels. Mercury concentrations have been found in breast milk from different countries across the world [6-9]. Mercury, one of the first ten chemicals of public health concern by WHO, is used in various household and industrial products such as bulbs, cosmetics, pharmaceuticals, thermometers, and mining. The main pathways of exposure to mercury are from occupationally exposed adults, accidental exposure, mercury mining, smelting, and artisanal gold mining [10]. Mercury bioaccumulates and biomagnifies in the food chain [11]. Fish consumption has been identified as the utmost pathway of exposure to methylmercury, an organic form of mercury [7].

Unfortunately, breastfeeding is one of the ways of eliminating the environmental toxic chemical burden for mothers [12]. The accumulated toxic chemicals in the mother are excreted into the breast milk during milk production are readily transferred to infants and easily absorbed [13]. For infants, these exposures may harm the development of the central nervous system, leaving a life-long defect on their cognitive abilities $[14,15]$. $\mathrm{Hg}$ is noxious to the developing brain, neurological functions, and can obstruct the natural detoxification pathways of the liver, kidneys, skin, and bowel [16]. Hg can cause problems in the endocrine, reproductive, and immune systems. Its lipophilic nature aids movement across the alveoli and also distributes itself in fatty tissues in the body.

Artisanal gold mining in Ghana started several years back in the $4^{\text {th }}$ century which has led to land degradation, dust production, soil, and water pollution [17]. Obuasi, in the Ashanti region of Ghana, is a known area for gold mining. Statistics have shown that a greater population of the youth in Obuasi are engaged in artisanal gold mining activities [18]. Artisanal gold mining (ASGM) is identified as the largest source of mercury pollution of the environment as countries in East and Southeast Asia, Sub-Saharan Africa, and South America are the major contributors to mercury in the environment [19]. Since amalgamation is a cheaper and easier method of gold extraction, the use of mercury in mining by artisanal gold miners in Obuasi areas is escalating. It was estimated that $80.4 \%$ of mercury imported into Ghana is used by the mining sector [20]. Inappropriate handling and disposal of mercury by these miners have to lead to pollution in the environment. Researches have reported levels of toxic metals including mercury in Obuasi and other parts of Ghana are in the water, soil, air, vegetables, blood, nails, urine, fish, 
sediment, and hair [21-24].

Most women living in mining communities within Ghana often depend directly or indirectly on mining activities for their livelihood. Some are miners; others assist their husbands or relations to mine, while others live with relatives who mine. Some women trade in mining areas as there is high patronage of goods and services in these areas. Mostly, miners carry out the gold extraction at homes since they do not want others to see their yield. Mothers in the municipality get exposed to mercury contamination through inhalation of mercury vapour during extraction, ingestion and dermal contact as some of the mercury accidentally settles in food and surfaces. There is a high risk of infants in mining communities receiving mercury through breastfeeding since lactating mothers can transfer mercury burden to their children [12].

Despite this risk associated with exposure of lactating mothers and infants to mercury in the Obuasi Municipality, little information is available on mercury levels in breast milk in the Municipality. Assessing the presence and quantity of mercury in the breast milk will provide information on the maternal toxic burden, and also serves as a marker for prenatal exposure to $\mathrm{Hg}$.

\section{METHODOLOGY}

\subsection{Study area}

The Obuasi Municipality, known for its gold resource, is located in the Ashanti Region of Ghana and lies between latitudes $5^{\circ} 35^{\prime} \mathrm{N}$ and $5^{\circ} 65^{\prime} \mathrm{N}$, and longitudes $6^{\circ} 35^{\prime} \mathrm{W}$ and $6^{\circ}$ $90^{\prime} \mathrm{W}$ (Figure 1). It covers a land area of $1624 \mathrm{~km}^{2}$ and has a population of about 168,641 [25]. Rocks in the Municipality are mostly of Tarkwain (Pre-cambrian) and Upper Birimian formation which is noted for their rich mineral-bearing potentials. The Municipality has an undulating terrain with most of the hills rising above 500 meters above sea level. The mean annual rainfall ranges between $1250 \mathrm{~mm}$ and $1750 \mathrm{~mm}$. Temperatures are uniformly high all year and the average annual temperature is $25.5^{\circ} \mathrm{C}$. The relative humidity is quite high, $(75 \%-80 \%)$ in the wet season. The vegetation is predominantly a degraded semi-deciduous forest. The forest consists of limited species of hardwood, which are harvested as timber. Farming is the preoccupation of the people but most of the youth ASGM activities most often the illegal way. Other occupation includes mining, craftsmanship, sales and services, and other professional jobs [25]. Figure 1 shows the map of the study area and sample locations.

\subsection{Sampling}

Breast milk samples were collected in seven hospitals in the Obuasi Municipality after permission has been granted by Obuasi Municipal Health Directorate.

Sampling was done at the Reproductive and Child Health $(\mathrm{RCH})$ centers in the seven health facilities (Obuasi government hospital, SDA hospital, Bryant Mission hospital; St. Cecilia clinic at Ahansonyewodea, Jemima Maternity Clinic located at the Obuasi central market, and two Community Health Planning Services (CHPS) compounds at Adaasi and Sanso. Breast milk samples were collected from 48 mothers in the selected hospitals and clinics in the Municipality. The samples were collected on days when mothers visit the hospitals and health centers for Child Welfare Clinic (CWC) popularly called "weighing".

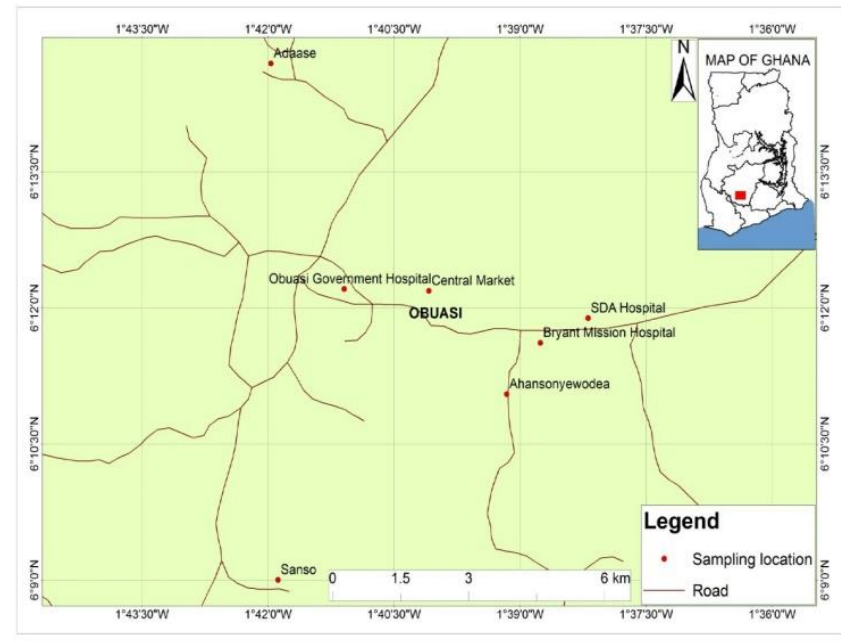

Figure 1. Map of sample locations

In each health facility, lactating mothers were briefed on the study, its purpose, scope, procedure, the confidentiality of information, and participation. Mothers who agreed to take part in the study signed or thumb printed on the consent form before expressing the milk. In each facility mothers involved in the study were given different rooms where they had their privacy. Breasts and hands of the lactating mothers were washed with distilled water before expressing the milk manually into well-conditioned glass bottles. A questionnaire was administered to inquire about the basic live style of the mothers. The breast milk samples were labeled and carried in an ice chest containing ice packs to the Pesticide Residue Laboratory at the Ghana Standard Authority. There, they were kept in the freezer at $-20^{\circ} \mathrm{C}$. The samples were then transported to Research Centre for Toxic Compounds in the Environment (RECETOX), Masaryk University, the Czech Republic in a biological sample box with dry ice for laboratory analysis.

\subsection{Sample analysis}

\subsubsection{Determination of total mercury ( $\mathrm{THg})$}

The breast milk samples were analysed at the Research Centre for Toxic Compounds in the Environment (RECETOX), Masaryk University. Total $\mathrm{Hg}$ concentration was determined using advanced mercury analyser (AMA254 Altech Corp., Czech Republic). Determination is based on atomic absorption spectrometry with thermal decomposition of samples followed by an amalgamation of mercury vapour. An Aliquot of $0.2 \mathrm{ml}$ was used and analyses were performed in duplicates. Quantification was done using a calibration curve from Mercury Analyser AMA-254 (Figure 2). The analyses were performed in duplicates to check for precision. The detection limit of the instrument is $<0.01 \mathrm{ng}$.

\subsubsection{Determination of methylmercury $(\mathrm{MeHg})$}

An aliquot of milk $(2 \mathrm{~mL})$ was spiked with $0.02 \mathrm{~mL}$ of the ${ }^{198} \mathrm{Hg}$-enriched methylmercury aqueous solution $(10 \mathrm{ng} / \mathrm{mL})$ and mixed with $1 \mathrm{~mL}$ of $37 \% \mathrm{HCl}$ and $1 \mathrm{~mL}$ of $17 \% \mathrm{NaBr}$ solution. The sample was then extracted twice with $3 \mathrm{ml}$ of toluene and the combined organic extract was subjected to back-extraction with $0.5 \mathrm{ml}$ of $1 \%$ L-cysteine aqueous solution. The final analysis was performed by HPLC-ICP-MS technique. The volume of the sample was injected into the HPLC system was $100 \mu \mathrm{L}$. Mobile phase $0.05 \%$ L-cysteine in the water, Flow rate - $1 \mathrm{~mL} / \mathrm{min}$ Reversed-phase 
chromatographic column (Synergi Hydro-RP, 150mm $\times 4.6$ $\mathrm{mm}, 4 \mathrm{um}$ ) was used for mercury speciation and an Agilent 7700x ICP-MS was used for $\mathrm{MeHg}$ detection with a detection limit of $<0.003 \mathrm{ng}$.

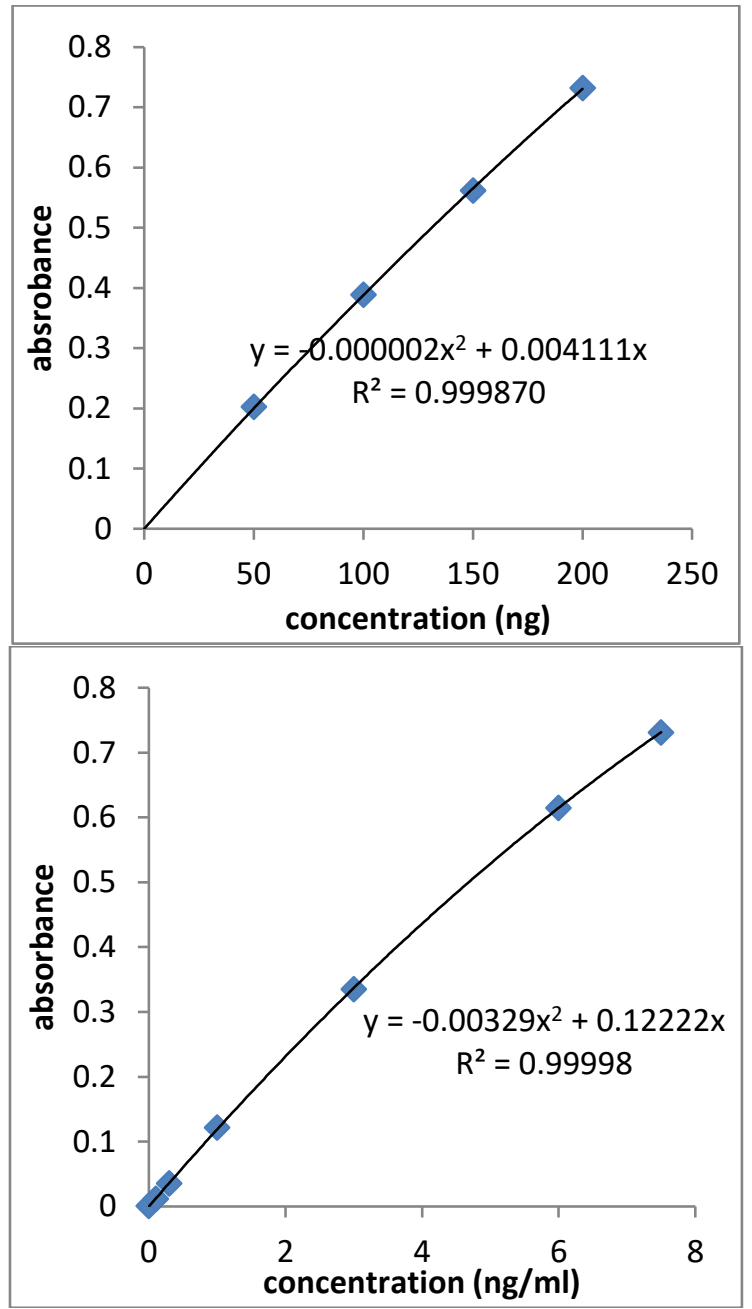

Figure 2. Calibration curve for total mercury

\section{RESULTS}

\subsection{Response from the questionnaire}

The age range of the mothers who expressed their breast milk was from 16 to 40 years and their infants were between the ages of 3 weeks to 1.1 years. The age of the infants was grouped into ages less than 3 weeks, 3 to 4 weeks, 5 to 8 weeks, and greater than 8 weeks. The majority of them were found to be among more than 8 weeks. Infants less than three weeks were not captured because most mothers start visiting the child welfare clinic or centers from age of 4weeks expect they have a special case. The response showed that 22 were primiparas (firstborn mothers) whiles 26 of them were multiparas (multiple births). This survey was conducted to investigate the level of the pollutants associated with the number of births. It is assumed that firstborn mothers have neither transferred any of the possible burdens to their infants and so have a high pollutant burden than multiparas.

18 out of the 50 mothers had lived in Obuasi for ten or more years while 32 of them have lived there for less than 10 years.
The mothers were involved in different occupations and some were housewives. The majority of them were traders followed by hairdressers, housewives, seamstress, miners and students, farmers, and teachers in descending order (Figure 3). None of the mothers had ever fixed dental amalgam in their teeth.

\section{(1) Dietary habit of mothers}

None of the mothers was a vegetarian they all consumed meat, fish, and vegetation. It is known that fish accumulate persistent organic pollutants and mercury pollutants from their habitat. Response gathered on fish consumption shows that the mothers are frequent fish consumers both the sea and freshwater fishes but consumptions of sea fishes are regular than freshwater. The response showed that mothers consume fish more often than meat and milk.

\section{(2) Source of drinking water}

The investigation showed sources of drinking water mothers use are borehole and pipe water from the Ghana Water Company. Water bodies in the municipal are heavily polluted due to illegal mining activities as a result residents do not use water from streams and rivers. 68\% 32\% drink from boreholes and pipe-borne water respectively.

\section{Mothers occupation}

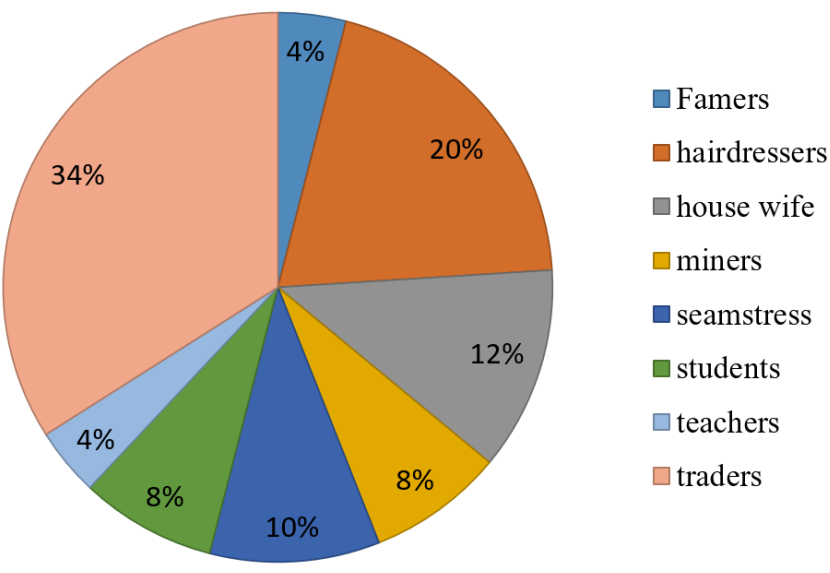

Figure 3. Chart of mothers occupation

\subsection{Total and methylmercury in breast milk}

Table 1. The concentration of total and methyl mercury in breast milk

\begin{tabular}{ccc}
\hline & Total Mercury $(\boldsymbol{\mu g} / \mathbf{L})$ & Methyl mercury $(\boldsymbol{\mu g} / \mathbf{L})$ \\
\hline Range & $0.080-2.320$ & $0.008-0.734$ \\
Mean & 0.404 & 0.183 \\
Median & 0.320 & 0.1145 \\
Std. Deviation & \pm 0.351 & \pm 0.154 \\
Variance & 0.124 & 0.024
\end{tabular}

Notes: 1 . The mean concentration of THg in the breast milk was $0.4043 \pm 0.35$ $\mu \mathrm{g} / \mathrm{L}$ (STD). 2. The concentration ranged from 0.080 and $2.320 \mu \mathrm{g} / \mathrm{L}$. 3. The mean concentration of $\mathrm{MeHg}$ in the breast milk was $0.1829 \pm 0.15 \mu \mathrm{g} / \mathrm{L}$ (STD). 4. The minimum and maximum concentrations of 0.008 and $0.734 \mu \mathrm{g} / \mathrm{L}$ respectively (Table 1)

Below is a table comparing the $\mathrm{THg}$ result from this research to the results of other works (Table 2). 
Table 2. Comparison of $\mathrm{THg}$ result in other works

\begin{tabular}{ccr}
\hline Total Mercury concentration range & Location & Reference \\
\hline $\begin{array}{c}\text { 0.080 to } 2.320 \\
\text { (Th/L } / \mathbf{L}\end{array}$ & Obuasi Municipal & \\
281 to $318 \mu \mathrm{g} / \mathrm{L}$ & Texas & {$[26]$} \\
$135.39 \pm 63.71 \mu \mathrm{g} / \mathrm{L}$ & Abgogbloshie & {$[27]$} \\
1.36 and $63.5 \mathrm{ng} / \mathrm{g}$ & Ghana & {$[28]$} \\
\hline Total Mercury concentration range & Tarkwa and Obuasi & Reference \\
\hline $0.35-6.90 \mu \mathrm{g} / \mathrm{L}$ & Location & {$[9]$} \\
$0.0-2.45 \mu \mathrm{g} / \mathrm{L}$ & Ankara, Turkey & {$[5]$} \\
$0.3 \pm 0.1 \mu \mathrm{g} / \mathrm{L}$ & Iran & {$[7]$} \\
$<1.0$ to $149.0 \mathrm{mg} / \mathrm{l}$ & Swedish & {$[13]$} \\
$3.100 \pm 4.053 \mu \mathrm{g} / \mathrm{L}$ & Samples were from Indonesia, Tanzania Zimbabwe & {$[29]$} \\
$0.4 \pm 0.1 \mu \mathrm{g} / \mathrm{L}$ & Saudi Arabia & {$[30]$} \\
\hline
\end{tabular}

\subsubsection{Total mercury reaults}

Unexpectedly, the highest $\mathrm{THg}$ level was found in milk samples taken from a mother who lives in a non-mining community (JHC) whiles the least was from Ahansonyewodea a mining community (Ahansonyewodea). Three of the sampling areas were mining communities (Ahansonyewodea, Sanso, and Adaasi). It was discovered that the mothers from Ahansonyewodea had a median THg concentration lower than the three other mining communities. Sanso had the highest median concentration followed by Adaasi then followed by Jemima maternity clinic (JMC), Government hospital (GH), Bryant Mission Hospital (BMH), SDA Hospital (SDA), then Ahansonyewodea (Ahanso) Figure 4.

Total mercury concentration per sample area

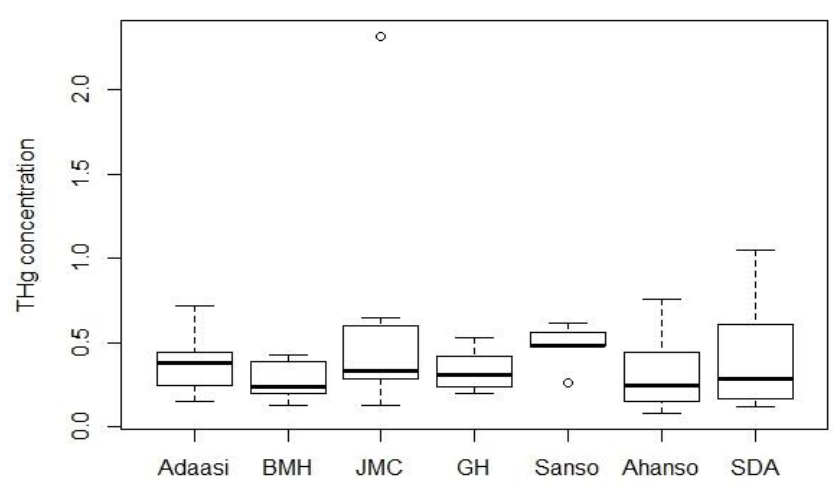

Figure 4. Plot of total mercury level areas of residence

A boxplot of the total mercury concentrations by the mother's occupation showed that miners had the highest median concentration of total mercury, followed by the hairdressers, teachers, seamstress, students, traders, and farmers in decreasing order. The highest concentration was found among the traders, for the values went beyond the upper quartile (Figure 5).

Plotting the mean concentration of $\mathrm{THg}$ with the ages of the mothers, it was discovered that mothers who fall in the 16-19 years age bracket had low $\mathrm{THg}$ concentration while the age 25 to 30 had the highest concentration (Figure 6).

As it is known that mothers may transfer their chemical burden to their children during breastfeeding, the average $\mathrm{THg}$ and $\mathrm{MeHg}$ concentration was related to the age groups of the children. This is to ascertain how much $\mathrm{Hg}$ the baby is likely to receive per every meal. It was observed that the total $\mathrm{Hg}$ concentration in the milk of mothers with babies at the age of
3-4 weeks have a higher median and mean than mother with an infant with ages greater than 4 weeks (Figure 7).

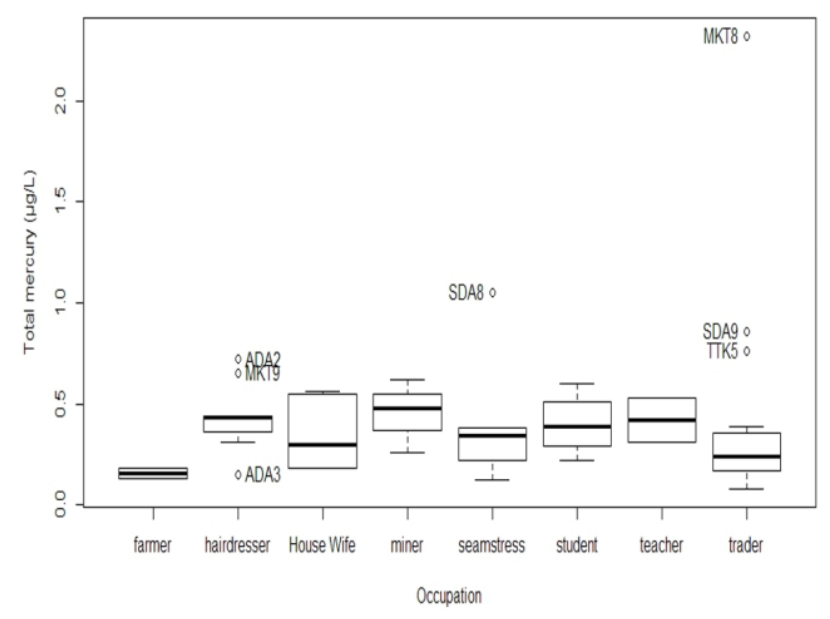

Figure 5. Boxplot showing the level of THg per mother's occupation

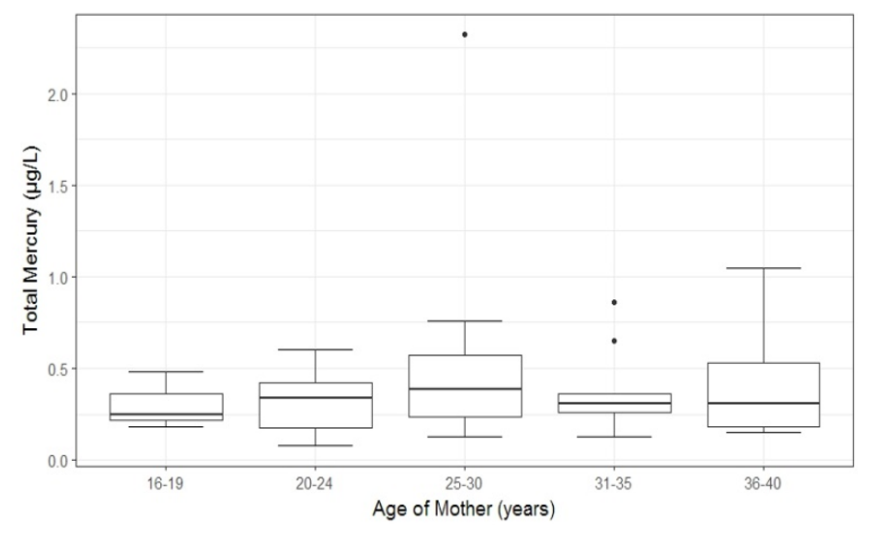

Figure 6. Plot of mother's age with Total mercury concentration

The correlation was found between the mean concentration of $\mathrm{THg}$ and $\mathrm{MeHg}$ for each age group and a coefficient of $\mathrm{R}^{2}=0.9887$ for $\mathrm{THg}$ and $\mathrm{R}^{2}=0.9909$ for $\mathrm{MeHg}$ were obtained. It was also observed that the total mercury concentration decreased with increasing age groups while the methylmercury slightly increased as the age groups increases. A similar observation on $\mathrm{THg}$ in breast milk was found to declined significantly from day 4 to 6 weeks by other researchers [7]. 
Total Mercury in mothers milk pre infant age

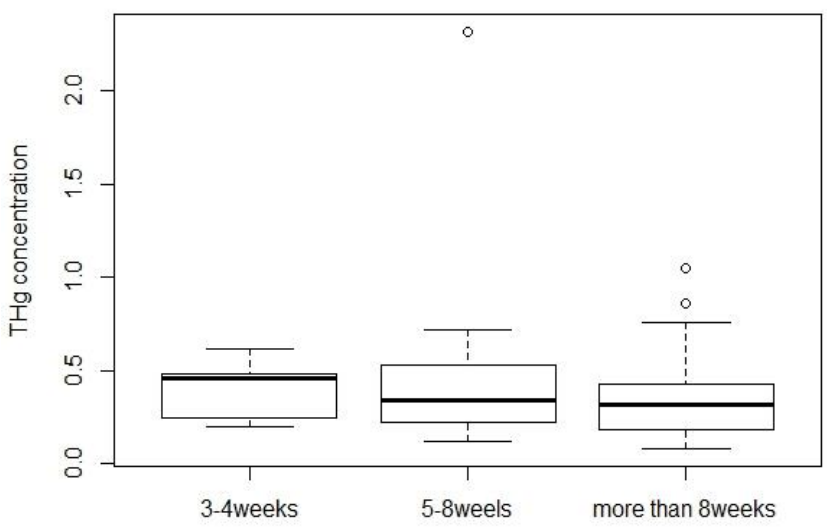

Figure 7. THg concentration of mothers per their children's age

\subsubsection{Methylmercury results}

The least and the highest methylmercury concentrations were found in the same community Ahansonyewodea. But the median concentration per the chart is found in JMC which is not a mining area. The three mining areas had varying $\mathrm{MeHg}$ concentrations with Adaasi being the highest followed by Sanso and Ahansonyewodea (Figure 8).

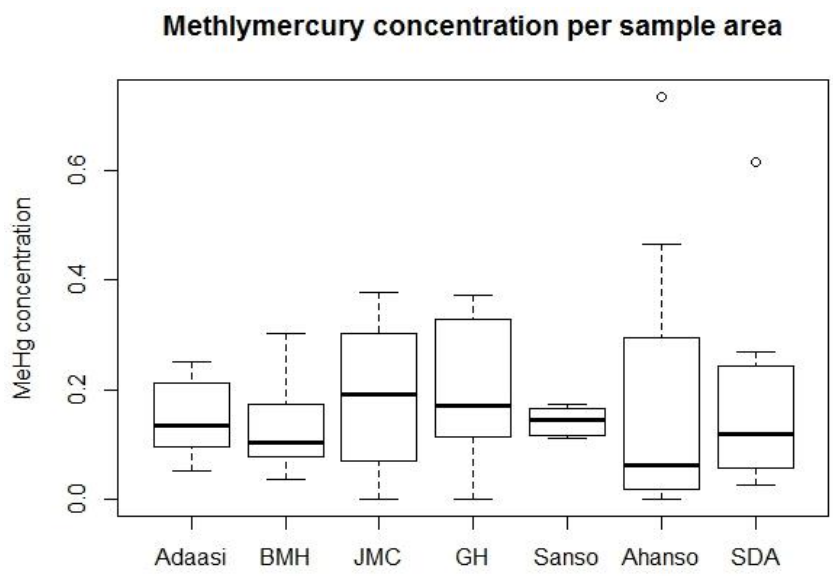

Figure 8. Plot of methylmercury with residence areas

\section{Frequency of fish consumption}

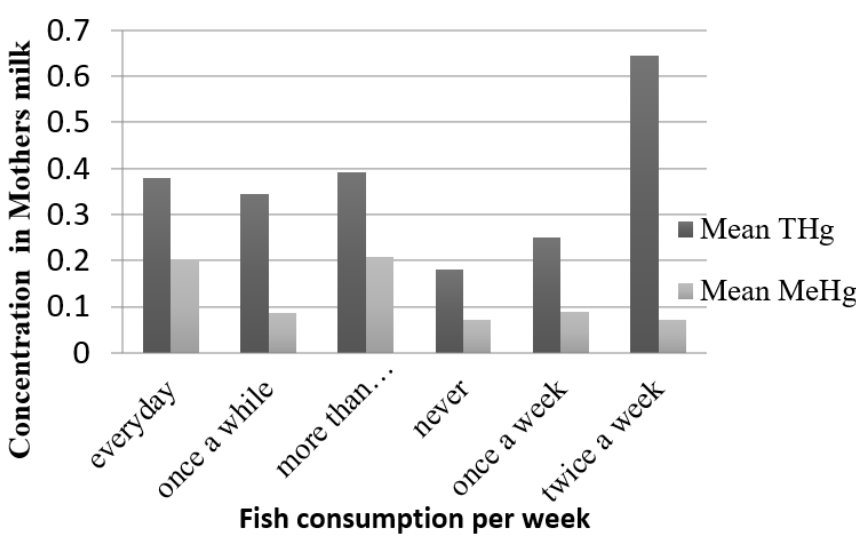

Figure 9. $\mathrm{THg}$ and $\mathrm{MeHg}$ concentration in mothers milk per frequency of fish consumption
Research suggests that frequent consumption of fish is associated with high methylmercury exposure [31-33], a paramount source of protein in Ghanaian diets. It was also observed that mothers who consumed fish more than twice a week and those on daily bases had higher Methylmercury levels (Figure 9).

$68 \%$ of the mothers drink borehole water as had a mean $\mathrm{THg}$ and $\mathrm{MeHg}$ concentrations ( 0.414 and $0.182 \mathrm{ng} / \mathrm{ml}$ respectively) in their breast milk higher than the $32 \%(0.391$ and $0.148 \mathrm{ng} / \mathrm{ml}$ $\mathrm{THg}$ and $\mathrm{MeHg}$ respectively) who drink from the pipe water. Below is a boxplot showing the distributions (Figure 10).

It is believed that primiparas (firstborn mothers) have a higher level of a chemical burden than multiparas (multiple birth mothers). This is because firstborn mothers have not freed any of concentration levels in their body. The boxplot of $\mathrm{THg}$ and $\mathrm{MeHg}$ concentration of the number of birth mothers confirms that firstborn mothers have higher mercury levels that the multiple birth mothers (Figure 11). Breast Milk samples from Iran revealed that firstborn mothers have higher mercury concentration than the multiple birth mothers [30]. Tutu et al. [34] recovered in her research on persistent organic pollutants in breast milk that firstborn mothers have a higher concentration of pollutants that multiple birth mothers confirming the observation in this research.

THg and MeHg Concentration per the sorce of drinking water

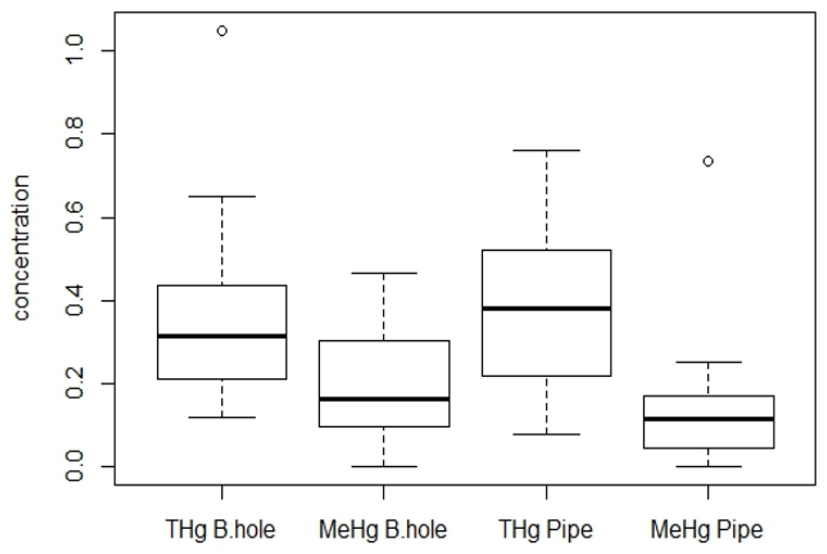

Figure 10. $\mathrm{THg}$ and $\mathrm{MeHg}$ concentration per source of drinking water

Mercury concentration per number of birth

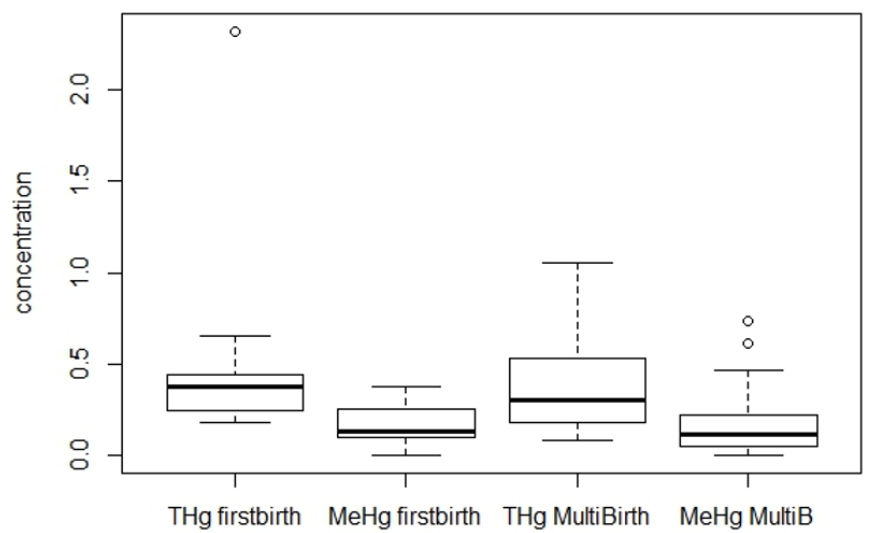

Figure 11. $\mathrm{THg}$ and $\mathrm{MeHg}$ concentration per number of births 


\subsection{Risk assessment of mercury levels}

Risk assessment involves evaluating and calculating the possible health effects individuals or people may experience due to exposure to hazardous substances. Minimal risk levels of chemicals are derived to determine if a substance is likely to pose an adverse effect on an individual. These values are set by considering the effect of the chemicals on different organs in the body and vulnerable groups. The US EPA has set a reference dose of $0.3 \mu \mathrm{g} / \mathrm{kg} /$ day for oral intake level for mercuric chloride (inorganic) and $0.1 \mu \mathrm{g} / \mathrm{kg} / \mathrm{day}$ for methylmercury [33].

The risk assessment in this study was evaluated by finding the hazard quotient of the ingestion exposure route by the infants. The evaluation was made for 1 month to 6 months old infants, that exclusive breastfeeding is encouraged. This calculation was made with the assumption that these infants will be breastfed for six months. First, the daily intakes of mercury by the infants were calculated with equation (1), followed by the calculation of the hazard quotients which was estimated by finding the ratio of the estimated daily intake to the reference value (2). The intake rate of breast milk for the infants used was taken from the mean intake of exclusively breastfed infants [35]. The mean concentrations of total mercury $(\mathrm{THg})$ and methylmercury $(\mathrm{MeHg})$ in this study were used while the average body weight was the mean weight of infants who visited the child welfare clinic in the Obuasi municipality. Estimated daily intake of mercury by the infants was calculated using

$$
\text { Estimated daily intake }(\mathrm{EDI})=\frac{C \times I R \times E F}{B W}
$$

$\mathrm{C}=$ concentration of the contaminate

$\mathrm{IR}=$ intake rate

$\mathrm{EF}=$ exposure factor

BW=body weight

$$
\text { Exposure factor }(\mathrm{EF})=\frac{F \times E D}{A T}
$$

$\mathrm{F}=$ Exposure frequency (7days/week)

$\mathrm{ED}=$ Exposure duration (4weeks/month)

AT $=$ Averaging Time (number of months $\mathrm{x}$ number of days in a month)

Number of days in a month used $=30$ days in a month

$$
\text { Hazard quotient }(\mathrm{HQ})=\frac{\text { Estimated Daily Intake }}{\text { reference Dose }}
$$

\begin{tabular}{|c|c|c|c|c|c|}
\hline $\begin{array}{l}\text { Age in } \\
\text { months }\end{array}$ & $\begin{array}{c}\text { Mean } \\
\text { Body } \\
\text { wt. } \\
\text { kg }\end{array}$ & $\begin{array}{c}\text { Estimated } \\
\text { daily } \\
\text { intake } \\
(\mathrm{THg}) \\
\mu \mathrm{g} / \mathrm{kg} \\
\text { wt./day } \\
\end{array}$ & $\begin{array}{c}\text { Estimated } \\
\text { daily } \\
\text { intake } \\
(\mathrm{MeHg}) \\
\mu \mathrm{g} / \mathrm{kg} \\
\text { wt./day } \\
\end{array}$ & $\begin{array}{c}\text { Hazard } \\
\text { Quotient } \\
\text { THg }\end{array}$ & $\begin{array}{c}\text { Hazard } \\
\text { Quotient } \\
\text { MeHg }\end{array}$ \\
\hline 1 & 3.8 & 0.0694 & 0.0314 & 0.2314 & $\begin{array}{c}0.31401 \\
\end{array}$ \\
\hline 2 & 6.8 & 0.0406 & 0.0184 & 0.1352 & 0.18351 \\
\hline 3 & 6.8 & 0.0417 & 0.0189 & 0.1389 & 0.18853 \\
\hline 4 & 8.5 & 0.0346 & 0.0157 & 0.1155 & 0.15665 \\
\hline 5 & 8.2 & 0.0366 & 0.0166 & 0.1221 & 0.16571 \\
\hline 6 & 8.4 & 0.0384 & 0.0174 & 0.1279 & 0.17355 \\
\hline
\end{tabular}

Table 3. Estimated daily intakes and hazard quotients for total mercury and methylmercury
Table 3 shows the result of the estimated daily intake and hazard quotient calculated.

Comparing the estimated intake obtained in this study [20] (3) to the reference dose endorsed by the US EPA $(0.3 \mu \mathrm{g} / \mathrm{kg} /$ day $)$, there is an indication that the intake dose of the infants is low. The mean daily intake estimated by Dahmardeh Behrooz et al. [30] was $0.065 \mu \mathrm{g} / \mathrm{kg}$ body wt./day was close to the estimated intake obtained for a month old infant in this study $(0.0694 \mu \mathrm{g} / \mathrm{kg}$ body wt. /day). The exposure dose calculated by for infants exposed to mercury from breast milk from Sweden women was $300 \mathrm{ng} / \mathrm{kg} /$ day [4].

\section{DISCUSSION}

The above results indicate that several factors relating to individuals' environment and style of living contributes greatly to level mercury in breast milk. Though the highest concentration was detected in a mother who does not stay in a mining area, the concentration in samples from the mining areas had a higher median. Most of the mothers from the nonmining communities ply mining communities to trade. This is due to the high patronage of food and other goods in illegal mining areas. Mothers may get exposed to mercury through inhalation, ingestion, or dermal contact and return to their place of residence in the non-mining community. It could be that their husbands are miners who may be burning the amalgam at home exposing the women to higher concentrations as revealed through questionnaires. ASGM miners are often unaware of the dangers associated with mercury [36]. They sometimes store the mercury in their bedrooms or handle it without using any protective gear hence, the family may get exposed to high mercury vapor levels. This could be an indication of higher levels among the illegal miners.

The emission rate of mercury by ASGM is 727 per tonnes/year worldwide, of which 316 per tonnes/year is the release from in sub-Saharan Africa [32]. The report points out that illegal mining contributes to high mercury emission hence the higher level of $\mathrm{THg}$ found among miners. Research by Rajaee et al. [24] on $\mathrm{Hg}$ levels in hair samples from Kejetia, in the upper east region, Ghana, found that illegal miners were exposed to mercury higher than non-miners.

The result showed that the ages of the mothers did not correlate $\left(\mathrm{R}^{2=0.0081)}\right.$ with the $\mathrm{THg}$ levels meaning the concentration of $\mathrm{Hg}$ in breast milk is independent of the mother's age. Yalçin et al. [9] found no correlation between the mother's age and mercury levels $\left(\mathrm{R}^{2}=0.011\right)$. Narjes et al. [5] also observed no significant change among age groups of mothers and the mercury concentration in the breast milk samples they analysed. Mothers who consume fishes from the freshwater had higher THg levels compared to those who take seawater fishes or both. The miner washes the sand into rivers thus contaminating the water bodies while some communities downstream may be fishing fish from it.

A strong conclusion cannot be made concerning the possible reason behind the high concentration among those who drink borehole water since the $\mathrm{Hg}$ levels in the water were not determined. A possible reason may be that borehole waters are most often not treated before use in Ghana however, pipe water in the municipality is treated from the Gyimi River. Also from the geological map of Ghana, there is evidence of major fault and shear zones in Obuasi and its surrounding areas. ASGM miners mainly carry out their activities in rivers, 
causing heavy pollution the water at the end. Rivers have connections with groundwater either as a discharge point and at times recharge, therefore the fractures in the geology may allow movement of heavy metals from polluted sites faster into groundwater. Run-off water may carry mercury from the illegal mining site into rivers or sip into the ground [37].

The result confirms that firstborn mothers had higher pollutant concentrations in their breast milk than multiple birth mothers [38]. The estimated daily intake obtained is lower than the reference dose set by the US EPA $(0.3 \mu \mathrm{g} / \mathrm{kg} / \mathrm{day})$, the hazard quotient for the exposure route through ingestion of breast milk by the infants' shows that there is a health risk. The values obtained show that one-month-old infants were at a high risk of exposure. A hazard quotient greater than 0.2 is considered unsafe, HQ of $\leq 0.2$ for any given route is considered acceptable [39]. Infants older than a month were lower than 0.2 , nevertheless, there is a health risk since the values are not far from it. Methylmercury causes impairment to the developing brain and can lower the IQ level of children [40].

The minimum temperature in Ghana $\left(21^{\circ} \mathrm{C}\right)$ is above the vaporizing temperature of mercury at $20^{\circ} \mathrm{C}$, this indicates that it can easily vaporize in our part of the world. Illegal miners do not wear protective clothing when working therefore they endanger their life as they get exposed to mercury. Mercury is toxic to the human, it affects the lungs, eyes, gingival (gum), skin, kidneys, and gastrointestinal tract. Methylmercury mainly affects the central nervous system. Inorganic mercury affects the immune system [33].

The result of this analysis has concentrations of total mercury in the samples that were lower than some level of mercury obtained in other research works (Table 2). Miners had average concentration than the other occupation. Also, mothers who consumed fish had high $\mathrm{Hg}$ concentration in their milk, especially from the fresh waters. Moreover, mothers who drank water from boreholes had high levels of $\mathrm{Hg}$ than those who drink from the pipe. This is an indication that individuals eating habits, environment, and style of living are factors that contribute to mercury exposure.

\section{CONCLUSION}

In a nutshell, more detailed studies on the sources and routes of exposure would help ascertain in-depth information on the exposure of mercury, to mothers in the municipality and country as a whole. Risk assessment studies should be conducted on mercury pollution in the area to determine the health risk associated with illegal mining activities. Mothers and miners should be educated more on the toxicity and exposure routes of mercury to protect their infants. Miners should be educated on how to handle mercury and wearing protective clothing and discourage the burning of amalgam in homes. There is a need for national guidelines on the use of mercury since Ghana is a Party to the Minamata Convention on mercury.

\section{ACKNOWLEDGMENT}

We express our sincere thanks and appreciation to Dr. Akwasi Amankwaa the Municipal Health Director and the management board of Obuasi Municipal Health Directorate for generously granting the permission and aid to sample. We thank Dr. Osei Fosu and his team at Pest Residue Laboratory (Ghana Standard Authority) for storing the samples till analysis. We would also like to acknowledge the expertise of the Research Centre for Toxic Compounds in the Environment (RECETOX), the Czech Republic, for the laboratory analyses which was supported by the Czech Ministry of Education, Youth and Sports (LO1214 and LM2015051). We are also grateful for the assistance provided by Mr. Peter Solaga, Mr. Thomas Opoku, Miss Evelyn Hotsonyame, and all the nurses who devoted their time to help during the sampling campaign. Our sincere appreciation goes to all mothers who participated by donating breast milk for the study. Thank you to all who contributed in diverse ways throughout the study process.

\section{REFERENCES}

[1] Natural Resources Defense Council. (2005). NRDC: Healthy Milk, Healthy Baby - Lead, Mercury, Cadmium, and Other Metals.

[2] World Health Organization (WHO). (2016). Risks from mercury for human health and the environment. WHO Regional Office for Europe. Copenhagen, Denmark.

[3] Kramer, R., Kakuma, M.S. (2002). The Optimal Duration of Exclusive a Systematic Review. World Health Organization. Switzerland: WHO Press, World Health Organization, 20 Avenue Appia, 1211 Geneva 27, Switzerland.

[4] Oskarsson, A., Hallén, I.P., Sundberg, J. (1995). Exposure to toxic elements via breast milk. Analyst, 120(3): 765-770.

[5] Narjes, O., Esmaili, A.S., Ghasempouri, S.M. (2013). Evaluation of mercury pollution in breast milk and Iranian infants' hair. International Research Journal of Applied and Basic Sciences, 4(9): 2857-2864.

[6] Abdollahi, A., Tadayon, F., Amirkavei, M. (2012). Evaluation and determination of heavy metals (mercury, lead and cadmium) in human breast milk. In E3S Web of Conferences, 1 : 41037. https://doi.org/10.1051/e3sconf/20130141037

[7] Björnberg, K.A., Vahter, M., Berglund, B., Niklasson, B. Blennow, M., Sandborgh-Englund, G. (2005). Transport of methylmercury and inorganic mercury to the fetus and breast-fed infant. Environmental Health Perspectives, 113(10): 1381-1385. http://doi.org/10.1289/ehp.7856

[8] Vieira, S.M., de Almeida, R., Holanda, I.B.B., Mussy, M.H., Galvão, R.C.F., Crispim, P.T.B., Bastos, W.R. (2013). Total and methyl-mercury in hair and milk of mothers living in the city of Porto Velho and villages along with the Rio Madeira, Amazon, Brazil. International Journal of Hygiene and Environmental Health, 216(6): 682-689. https://doi.org/10.1016/j.ijheh.2012.12.011

[9] Yalçin, S.S., Yurdakök, K., Yalçin, S., Engür-Karasimav, D., Coşkun, T. (2010). Maternal and environmental determinants of breast-milk mercury concentrations. Turkish Journal of Pediatrics, 52(1): 1-9.

[10] Agency for Toxic Substances and Disease Registry (ATSDR). (1999a). Public Health Statement Mercury, 120.

[11] Bella, N.L., Hilliker, A. (2003). Mercury in the environment. The Traprock, 2: 33-36. https://doi.org/10.1136/bmj.4.5838.489-c

[12] Mead, M.N. (2015). Contaminants in HumanMilk: 
Weighing the risks against the benefits of breastfeeding W. Environmental Health Perspectives, 116(10): 427434. https://doi.org/10.1017/CBO9781107415324.004

[13] Bose-O'Reilly, S., Lettmeier, B., Roider, G., Siebert, U., Drasch, G. (2008). Mercury in breast milk - a health hazard for infants in gold mining areas? International Journal of Hygiene and Environmental Health, 211(5-6): 615-623. https://doi.org/10.1016/j.ijheh.2007.09.015

[14] Grandjean, P., Jørgensen, P.J., Weihe, P. (1993). Human milk as a source of methylmercury exposure in infants. Environmental Health Perspectives, 102(1): 74-77. https://doi.org/10.1289/ehp.9410274

[15] Dorea, J.G. (2004). Mercury and lead during breastfeeding. British Journal of Nutrition, 92(1): 21-40. https://doi.org/10.1079/BJN20041163

[16] McGuire, T. (2014). Chronic Mercury Poisoning and Amalgam (Silver) Fillings, 4-25.

[17] Tsikata, F.S. (1997). The vicissitudes of mineral policy in Ghana. Resources Policy, 23(1-2): 9-14.

[18] GSS. (2011). Ghana Multiple Indicator Cluster Survey with an Enhanced Malaria Module and Biomarker. Final Report.

[19] United Nations Environment Programme (UNEP). (2013b). Global Mercury Assessment 2013: Sources, Emissions, Releases, and Environmental Transport. UNEP, 1-44.

[20] Environmental Protection Agency Ghana. (2015). Environmental Protection Agency Ghana report on mercury; Ghana's submission.

[21] Donkor, A.K., Nartey, V.K., Bonzongo, J.C., Adotey, D.K. (2006). Artisanal mining of gold with mercury in Ghana. West Africa Journal of Applied Ecology, 9: 1-8.

[22] Kpan, J.D., Opoku, B.K., Gloria, A. (2014). Heavy metal pollution in soil and water in some selected towns in Dunkwa-on-Offin District in the Central Region of Ghana as a result of small scale gold mining. Journal of Agricultural Chemistry and Environment, 3(2): 40. https://doi.org/10.4236/jacen.2014.32006

[23] Nartey, V.K., Klake, R.K., Hayford, E.K., Doamekpor, L.K., Appoh, R.K. (2011). Assessment of mercury pollution in rivers and streams around artisanal gold mining areas of the Birim north district of Ghana. Journal of Environmental Protection, 2: 1227-1239. https://doi.org/10.4236/jep.2011.29141

[24] Rajaee, M., Long, R.N., Renne, E.P., Basu, N. (2015). Mercury exposure assessment and spatial distribution in a Ghanaian small-scale gold mining community. International Journal of Environmental Research and Public Health, 12: 10755-10782. https://doi.org/10.3390/ijerph120910755

[25] GSS. (2014). District Analytical Report Obuasi Municipality.

[26] Pugach, S., Clarkson, T. (2009). Prenatal mercury exposure and postnatal outcome: Clinical case report and analysis. Clinical Toxicology (Philadelphia, Pa.), 47(4): 366-370. https://doi.org/10.1080/15563650902866911

[27] Mends, E.M. (2016). Levels of Heavy Metals in Cattle and Human Milk Collected at Agbogbloshie, an E-Waste Dumpsite. University of Ghana School of Public Health, College of Health Sciences, University of Ghana. A Dissertation Submitted in Partial Fulfi. the University of Ghana.

[28] Bansa, D.K., Awua, A.K., Boatin, R., Adom, T., Brown-
Appiah, E.C., Amewosina, K.K., Okwabi, W. (2017). Cross-sectional assessment of infants' exposure to toxic metals through breast milk in a prospective cohort study of mining communities in Ghana. BMC Public Health, 112. https://doi.org/10.1186/s12889-017-4403-8

[29] Al-Saleh, I., Shinwari, N., Mashhour, A. (2003). Heavy metal concentrations in the breast milk of saudi women. Biological Trace Element Research, 96(1-3): 21-38. https://doi.org/10.1385/BTER:96:1-3:21

[30] Dahmardeh Behrooz, R., Esmaili-Sari, A., Peer, F.E., Amini, M. (2012). Mercury concentration in the breast milk of Iranian women. Biological Trace Element Research, 147(1-3): 36-43. https://doi.org/10.1007/s12011-011-9283-7

[31] United Nations Environment Programme (UNEP). (2008). Guidance for identifying populations at risk from mercury exposure, (August), 15-130.

[32] United Nations Environment Programme (UNEP). (2013a). Global Mercury Assessment, 1-24.

[33] Agency for Toxic Substances and Disease Registry (ATSDR). (1999b). Toxicological Profile for Mercury, 1-676. Atlanta, Georgia.

[34] Tutu, A.O., Yeboah, P.O., Golow, A.A., Kumi, S.A., Clarke, E., Fosu, P.O. (2013). Levels of Organochlorine pesticide residues found in the breast milk of some firstbirth mothers from a rural community (Ada) in Ghana, 54: 12668-12672.

[35] Butte, N., Lopez-Alaracon, M., Garza, C. (2002). Nutrient adequacy of exclusive breastfeeding for the term infant during the first six months of life. World Health Organization, 1-37.

[36] United Nations Environmental Program (UNEP). (2008). Module 3: Mercury Use in Artisanal and Small Scale Gold Mining. Mercury: A Priority for Action, 1-20.

[37] National Research Council. (2000). Toxicological effects of methylmercury. National Academies Press. https://doi.org/10.17226/9899

[38] Tutu, A.O., Yeboah, P.O., Golow, A.A., Denutsui, D., Blankson-Arthur, S. (2011). Organochlorine Pesticides Residues in the Breast Milk of Some Primiparae Mothers in La Community, Accra, Ghana. Research Journal of Environmental and Earth Sciences, 3(2): 153-159.

[39] Health Canada. (2012). Part I: Guidance on Human Health Preliminary Quantitative Risk Assessment (PQRA).

[40] Casarett, L.J., Doull, J. (2013). Toxicology: The Basic Science of Poisons. (and L. A. S. Andrea Seils, Susan R. Noujaim, Ed.) (6th ed.). United States: McGraw-Hill.

\section{APPENDIX}

Author's contribution

This manuscript was written through the contribution of the authors. They have approved the final version of the manuscript.

\section{Funding sources}

All financial support for this research was paid by the authors with the exception of the laboratory analysis which was supported by the Czech Ministry of Education, Youth and Sports (LO1214 and LM2015051). 